\title{
Using Workflow-based Systems for e-Services Provision
}

\author{
Silvia Llorente and Jaime Delgado \\ Distributed Multimedia Applications Group, Universitat Pompeu Fabra (UPF) \\ \{silvia.llorente, jaime.delgado\}@tecn.upf.es
}

\begin{abstract}
The use of electronic commerce is spreading day to day to reach environments that have been rather unexplored until this moment, such as governments and administrations. More and more, administrations offer on-line services to the citizens of their countries or regions. It is becoming necessary to have a mechanism for the formal definition of these on-line electronic services (or e-services). Doing so, we would be able to automatically build systems capable to manage these new e-services. An important feature of e-services is that a workflow can be defined to control their development. These concepts do not only apply to e-government, but also to e-business and e-commerce in general. Early experience on the provision of professional e-services has helped us to take this approach.
\end{abstract}

In this paper we present how e-services using workflow-based systems can be defined in a formal way with the target of building them automatically. For this purpose, we specify a method for expressing workflow information with XML and DAML-S and, more generally, to define workflow-based e-services. A functional model with the involved entities completes this. Finally, a real implementation of e-services is introduced. ${ }^{1}$

\section{INTRODUCTION}

We divide electronic commerce activities into two main categories depending on what is sold: products (tangible or not) and services. Each category comprises several steps to perform the purchase of a product or a service contract.

\footnotetext{
${ }^{1}$ This work has been partly supported by the Spanish Administration (TIC2000-0317-P4-05).
} 
The electronic commerce of products involves the search of the desired product, its request and, finally, the payment and delivery. If needed, post-sales support could be given to deal with customers' problems.

The electronic commerce of services (in short, e-services) also involves a search, but in this case we search for a professional, company or institution that offers the desired service. Then, an agreement phase is needed and, finally, the service is contracted. In the post-agreement phase, the service is developed. It may involve several actors or users that will be contacted as needed. Payment can be done in the agreement or post-agreement phases. This schema of e-services could be applied to any area inside e-commerce, e-business and e-government.

However, it is worth noting that electronic commerce of products and services have many things in common. For example, the phases that involve the sale of a good or a service are similar. In both cases, we have an identification phase, where the good or service (from now on we will refer to them generically as "item") is found. Then, there is the request phase, where the item is asked for. Next, we have the agreement phase, which involves payment and delivery of the selected item and, finally, the post-agreement phase (Gallego et al, 1998).

It is in the post-agreement phase where the differences appear. Whilst goods post-agreement phase usually involves a hot-line or post-sales support to solve customers' problems, if any, the e-service post-agreement phase is where the e-service is developed and a result is sent to the actor who contracted it. An e-service could be as simple as a report or advice request, or as elaborated as a full legal case, which, furthermore, involves several actors (lawyer, notary, court, administration, etc).

Nevertheless, there are other approaches to the definition of phases for electronic transactions, such as (Schmid et al, 1998).

\section{WORKFLOW AND E-SERVICES}

When the development of an e-service involves several actors, its control becomes more complex. It is also usual that these actors interchange some information. The activity of these actors inside an e-service should be controlled in some way, for example, with a workflow (Workflow Management Coalition Web page). The workflow controls the order in which the information is interchanged, who are the actors involved in every step, which are the steps that compose the development of an e-service, and so on.

There is also an underlying workflow in electronic commerce of products, with similarities and differences from e-services workflow. Workflow for electronic commerce of products usually involves two or three 
actors, as a maximum: the buyer, the seller and, sometimes, a financial institution. This workflow should control the phases for the purchase of a product through electronic commerce: identification, request, agreement (with payment and delivery) and, if needed, post-agreement.

In contrast, many actors may appear in the development of an e-service: The customer who wants to contract it, the professional who offers it, other professionals or administration/government institutions that are contacted during its development and, in some cases, financial institutions. The post-agreement phase is the one that differentiates electronic commerce of products from e-services, since, in the later, it can be divided in several steps. This is why a specific workflow has to be constructed and we will focus in this subject in this paper.

Not only professionals can offer e-services, but also administrations and governments can do it. If a professional offers an e-service, we are referring to e-commerce or e-business. If an administration or a government offers an e-service, we are talking about e-government.

\section{E-SERVICES SPECIFICATION}

In the following sections we describe in detail how to specify an e-service. First of all, we show the metadata needed by a system that wants to implement e-services. Then, we explain how XML (W3C XML Web page) is used for the definition of e-services and the data needed by the workflow.

\subsection{Metadata associated to an e-service}

There are different kinds of metadata associated to an e-service:

- Metadata referring to the complete system: e-Service contractual conditions, users offering the e-service, user contact information, e-service guidelines.

- Metadata that define the skeleton of a specific e-service: Users involved (roles), associated documentation, e-service steps to accomplish with the objectives.

- Metadata for a working e-service: Users appearing in the e-service, status of the associated documentation, steps taken in the e-service and its state (in progress, finished, etc).

Apart from metadata, there could be documents associated to the e-services, either in their active phase (documents needed for the development of the e-service that depends on its nature) or in their initial phase (for example a contractual document). 


\subsection{Workflow definition using DAML-S}

For the formalisation of workflow definition, we use the XML language because of its wide use and support by the major software vendors and companies. We have studied different initiatives in workflow and process definition using XML and we have finally chosen DAML-S (DAML stands for DARPA Agent Mark-up Language, and the S stands for services).

DAML (Hendler et al, 2001) is an initiative for the creation of ontologies for any domain, which permits the description of sophisticated class definitions. It extends RDF (Resource Description Framework) (W3C RDF Web page), a resource description language, which allows the description of basic structures such as classes and properties. DAML-S (DAML Service Coalition) is a vocabulary created for process description on top of DAML.

The e-services inside the system are being described as XML documents using DAML-S. In particular, these descriptions will be able to describe e-service families as well as specific instances of an e-service.

The workflow definition of an e-service can be done a priori or a posteriori. For defining an e-service a priori, we need to know in advance the e-service characteristics in order to represent them into XML format before starting the e-service. For the a posteriori definition, the e-service is being defined as it is being developed. This permits, once the e-service finishes, to define a new e-service family with the XML representation defined during e-service development.

\subsubsection{Predefined e-services}

When a predefined e-service is contracted, it has to be adapted to its specific characteristics. This adaptation may consist on:

- Defining the users, which will represent the general roles described in the e-service.

- Defining deadlines for information delivery.

- Adding new steps/users not defined in the general e-service.

\subsubsection{Non predefined e-services}

When an e-service without predefined workflow is contracted, it has to be constructed as the e-service is developed. This construction may consist on:

- Creating the steps of the e-service and defining their inter-relationships.

- Inserting users in the e-service.

- Inserting steps in the e-service.

- Defining the information that users have to interchange. 
Later on, some information has to be extracted from this new e-service in order to convert it into a new predefined e-service.

\subsubsection{Example of definition of an e-service}

As an example, the e-service definition of a process using DAML-S is shown in figures 1 and 2.

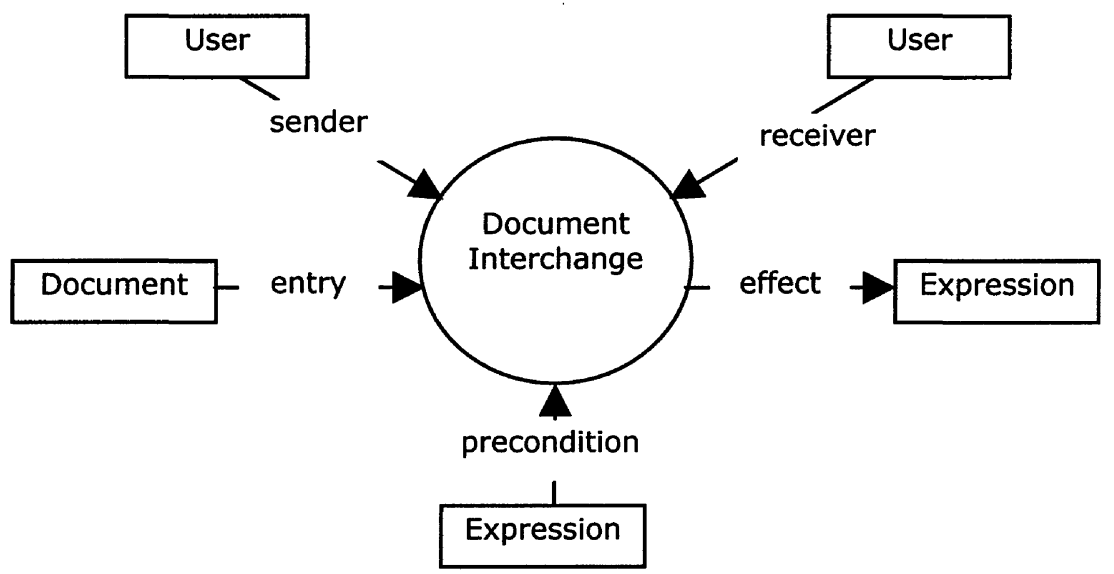

Figure 1. Sample process Document Interchange

Figure 1 shows the sample process Document Interchange. In this process, a user sends a document to another. This interchange will imply some effect; for instance, the document is accepted and the e-service can move onto a next step, or the document is not accepted and this process should be repeated.

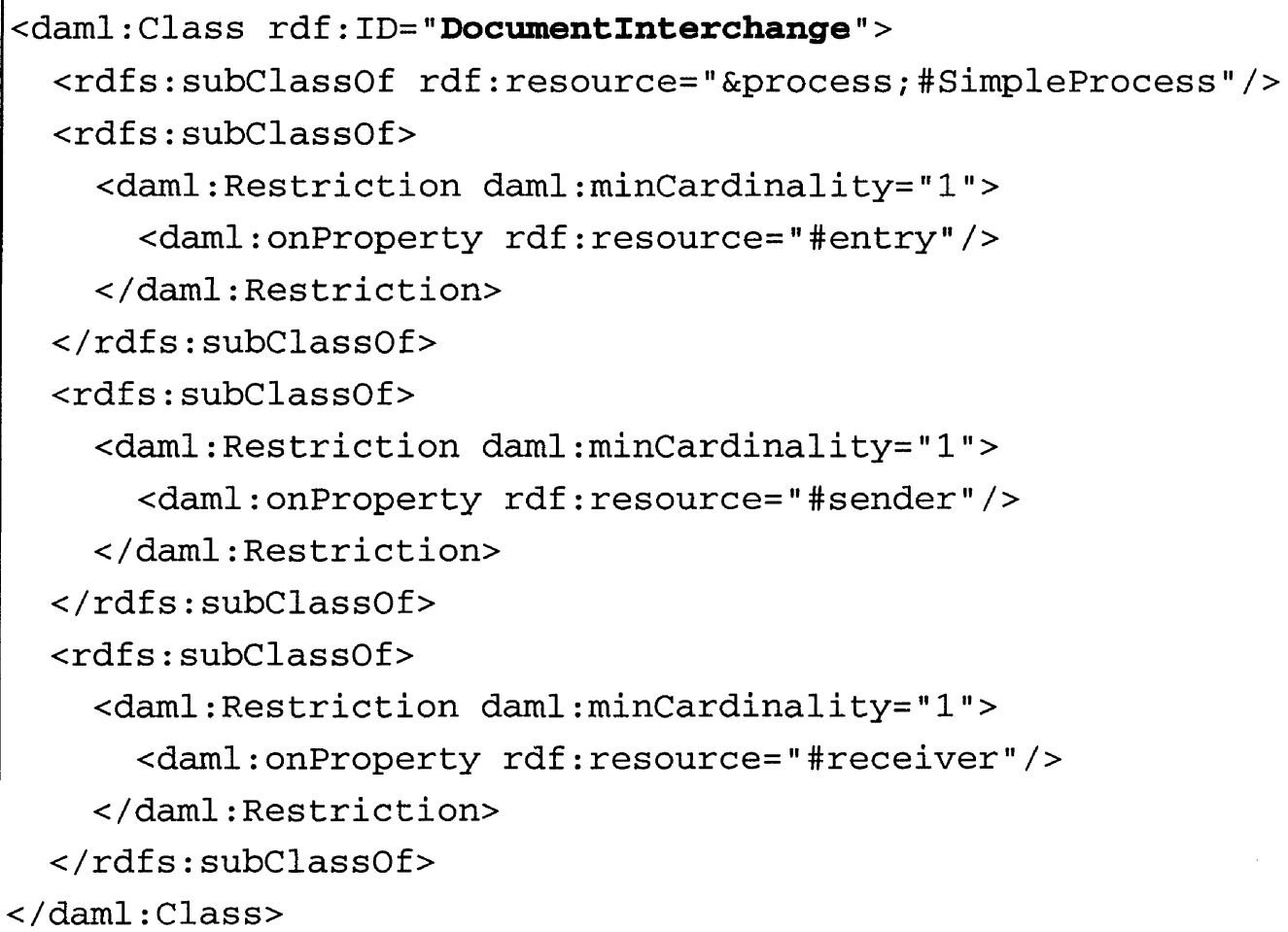




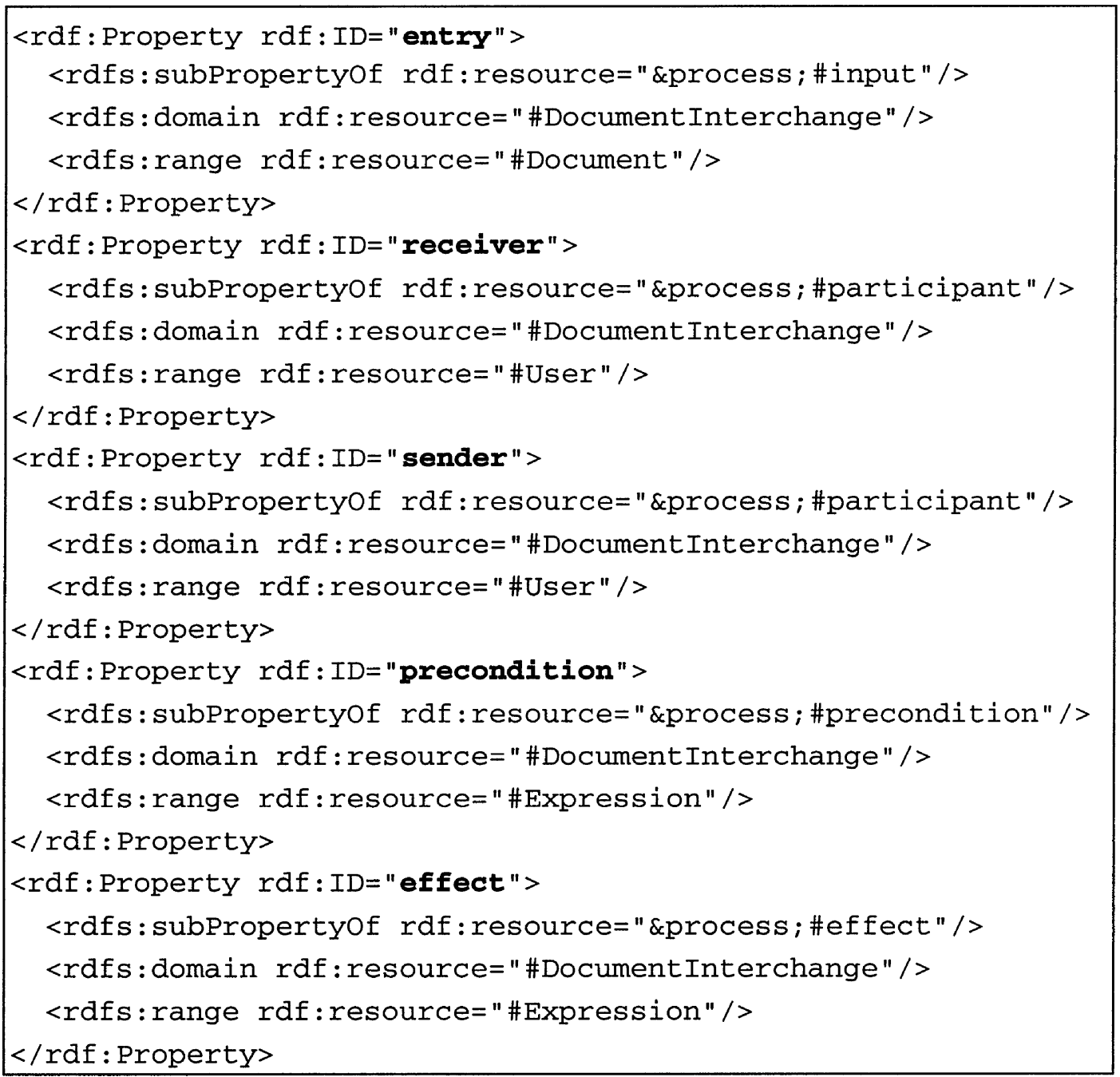

Figure 2. DAML-S representation for Document Interchange process

Figure 2 shows the serialisation of the Document Interchange process using the DAML-S syntax.

\subsection{Comparison with ebXML}

In this section we want to briefly compare our proposal of representation of processes using XML language with ebXML (ebXML Web page), one important initiative in the definition of complex business processes. Our proposal and ebXML have some things in common, but also several dissimilarities.

The main similarity between ebXML and our proposal is that many partners collaborate to perform a complex process, which, in general, is composed by several activities.

Another important similarity is the concept of document flow, as we also define document interchanges between the roles participating in an e-service. 
On the differences side, we have to emphasize that our main objective is to represent a wide range of processes from completely predefined to dynamically created ones, to offer them through electronic commerce. We do not want to specify XML messages related to business transactions as ebXML does. The kind of services we are able to represent are legal, medical or joint edition services, whilst ebXML refers to more classical definition of business processes, for instance, a Purchase Order request.

\section{CONTROL AND INFORMATION FLOW}

The control and information flow can be seen from two different points of view. The first one is related to the workflow control mechanism and how it is generated. It has already been introduced in the previous section, when we have talked about predefined and non-predefined e-services. Similar concepts were already introduced in (ITU-T, 1997).

The second point of view is related to the storage of the information in the system. We have two kinds of information: documentation information (DOCi) and workflow control information (WFCi).

From the first point of view, we can distinguish among the following possibilities:

- Predefined workflow: It is a special case of the predefined e-service. If we have a predefined workflow, then the workflow is completely defined before starting the e-service and the users must follow it (it is not modifiable).

- Generated on the fly: It corresponds to the non-predefined e-service. The workflow of the e-service is unknown and participating users indicate what has to be done next for the correct development of the e-service.

- Mix of the two possibilities: It corresponds to the predefined e-service. We work with a predefined workflow that can be extended/modified to be adapted to each particular working e-service.

From the second point of view, we have the following possibilities:

- Workflow control:

- Centralised: Only one of the users involved in the e-service has the WFCi and informs the rest that they have to perform some action.

- Distributed control: The WFCi moves from user to user, when they have to perform some action.

- DOCi storage:

- Centralised: The DOCi is always stored in the same location.

- Distributed information storage: The DOCi moves from user to user.

Both points of view can be combined to provide the system we need: Centralised control and DOCi storage, distributed control and DOCi storage, 
centralised control and distributed DOCi storage or distributed control and centralised DOCi storage.

The information of the action/s to be done and the user in charge of the action is included in the WFCi.

In case of distributed control, the user who has the control calls the operation/s needed to perform the action. If the control is centralised, the user controlling the workflow advises to the corresponding user of the action that has to perform.

\section{FUNCTIONAL MODEL FOR WORKFLOW-BASED E-SERVICES}

Our functional model describes the entities that can be found in an e-service. In the following, we show in more detail these entities and their relationship. The operations offered by the entities as well as a preliminary functional model were already described in (Llorente et al, 2001).

\subsection{Entities}

We have identified five different main classes of entities needed in an e-service. They are:

- User entities: The entities that directly dialogue with final users or represent final users (human or machines).

- Knowledge entities: The entities that have the intelligence or knowledge inside the distributed system. They are divided into Server entities and Service entities.

- Server entities: The entities that have the intelligence or knowledge related to the complete system.

- Service entities: The entities that have the intelligence or knowledge related to the e-services inside the system.

- Notification entities: Entities that offer an interface for the sending of notifications among the rest of entities (normally user entities and knowledge entities). They usually have store-and-forward behaviour.

- Document entities: The entities that are in charge of the management of the documents needed by the different entities of the workflow system.

- Metadata entities: The entities that deal with the system metadata.

This entity classification will permit us to see each entity as a separate agent with a very specific functionality, and to use an agent platform to implement a system to provide e-services. This platform will offer us most of the needed functionality for monitoring and communicating the different entities collaborating in such a system.

Figure 3 shows the entities together with their relationship. 


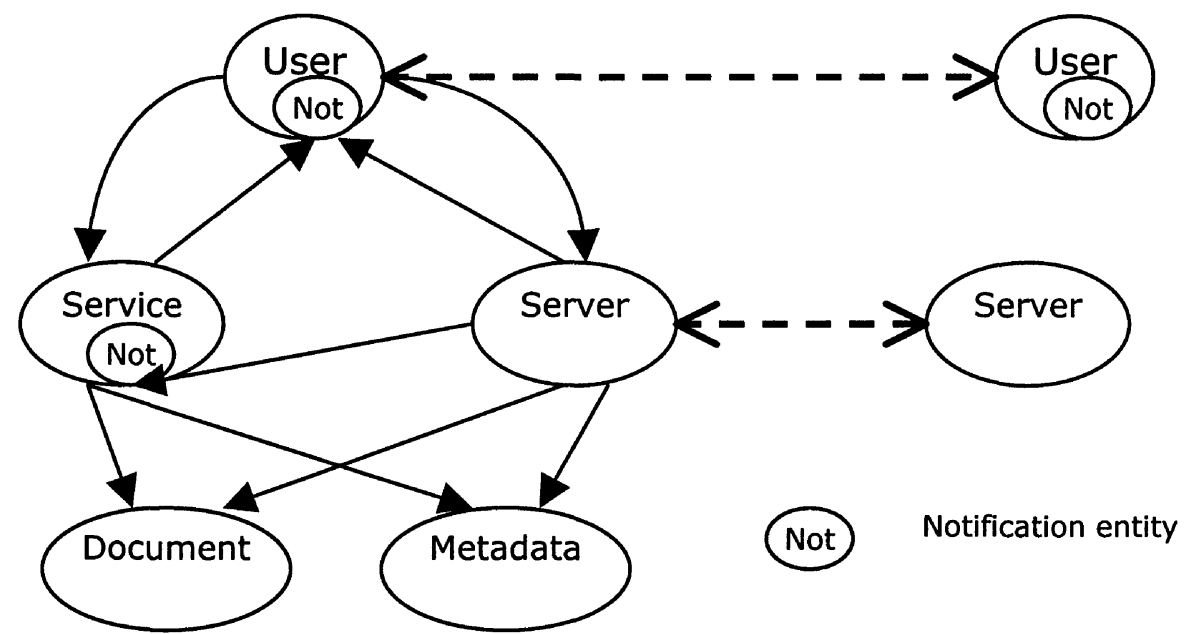

Figure 3. Entities and their relationship in the functional model for the electronic commerce of workflow-based e-services

This is only a possible functional model. We can easily think about some different models: several notification entities per user entity, several document and metadata entities, document and metadata entities accessible directly from user entities, etc. We can adapt the functional model to the needs of any specific system. In the figure, discontinuous arrows represent the communication between peer entities, and normal arrows indicate which entities communicate through operations. The arrows go from operation caller to operation provider. Results go on the opposite direction.

The server entities that appear in Figure 3 belong to different systems. It could be interesting to communicate them in order to interchange user profile information, e-service workflow control files and other information related to their operation. For example, if we have a system installed in collaborating companies or administrations, but they do not share information, we can interchange the information of the new e-services created by one of them. This scenario can be extended at will (as many companies as you want).

\section{IMPLEMENTATION OF A WORKFLOW E-SERVICE: THE TRADE PROJECT}

We started the work that led to our current model in the TRADE (TRADE Web page) (TRiAls in the Domain of Electronic commerce) project, part of the ACTS (ACTS Web page) programme (project 328) of the European Commission. In that project, we defined the workflow of administrative and legal services to provide them through electronic commerce as explained in (Llorente et al, 2000). 
The functional model of the TRADE system fits very well with the general one presented in section 5. The system implemented in the TRADE project consisted on a centralised server (the TRADE Server), which provided the functionality to the user entities of the system. This centralised server was the knowledge entity. It also contained the document and metadata entities inside. In Figure 4, the different user entities and their roles in the system (customers or suppliers) are shown. Note that the lawyer may act either as a customer or as a supplier.

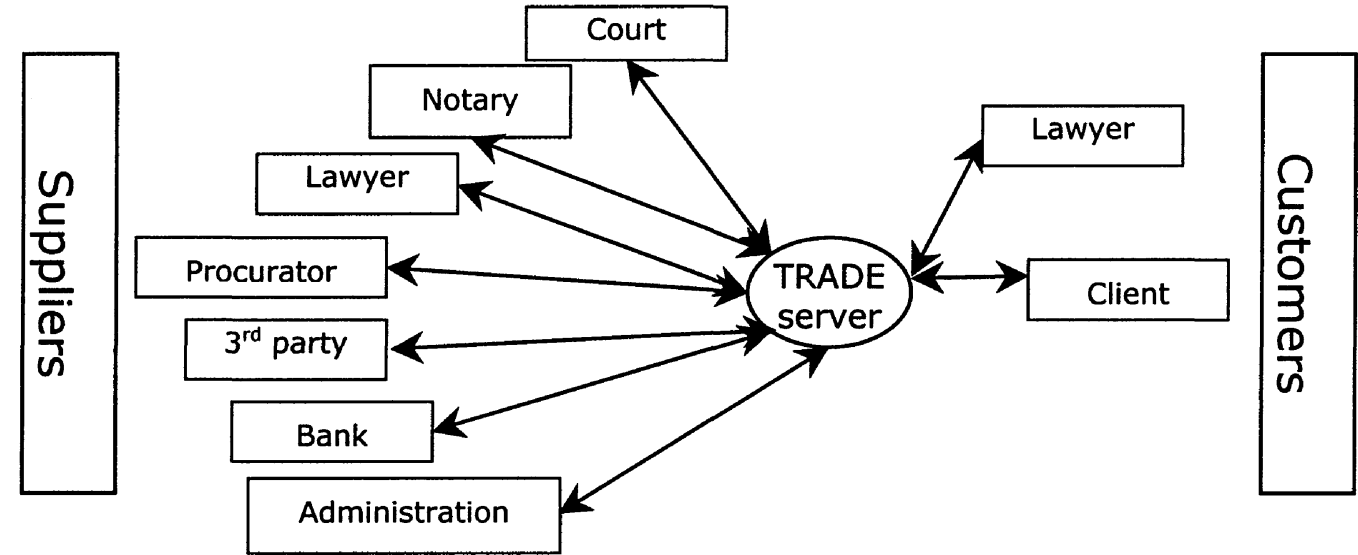

Figure 4. TRADE system functional model

After the finalisation of this project, more than one year ago, we have reengineered the system in the context of the running project AREA2000, cofunded by the Spanish Administration.

Now, we have split the knowledge entity into system and service entities with the purpose of constructing a new TRADE system using agent technologies and DAML-S for the workflow definition. Figure 5 shows the new functional model corresponding to this system. We still have a centralised server (the newTRADE server), which offers some part of the functionality to the user entities. The newTRADE server is the server entity. The rest of the needed functionality is offered by the service entities, which are created by the server entity when an agreement between user entities is done. 


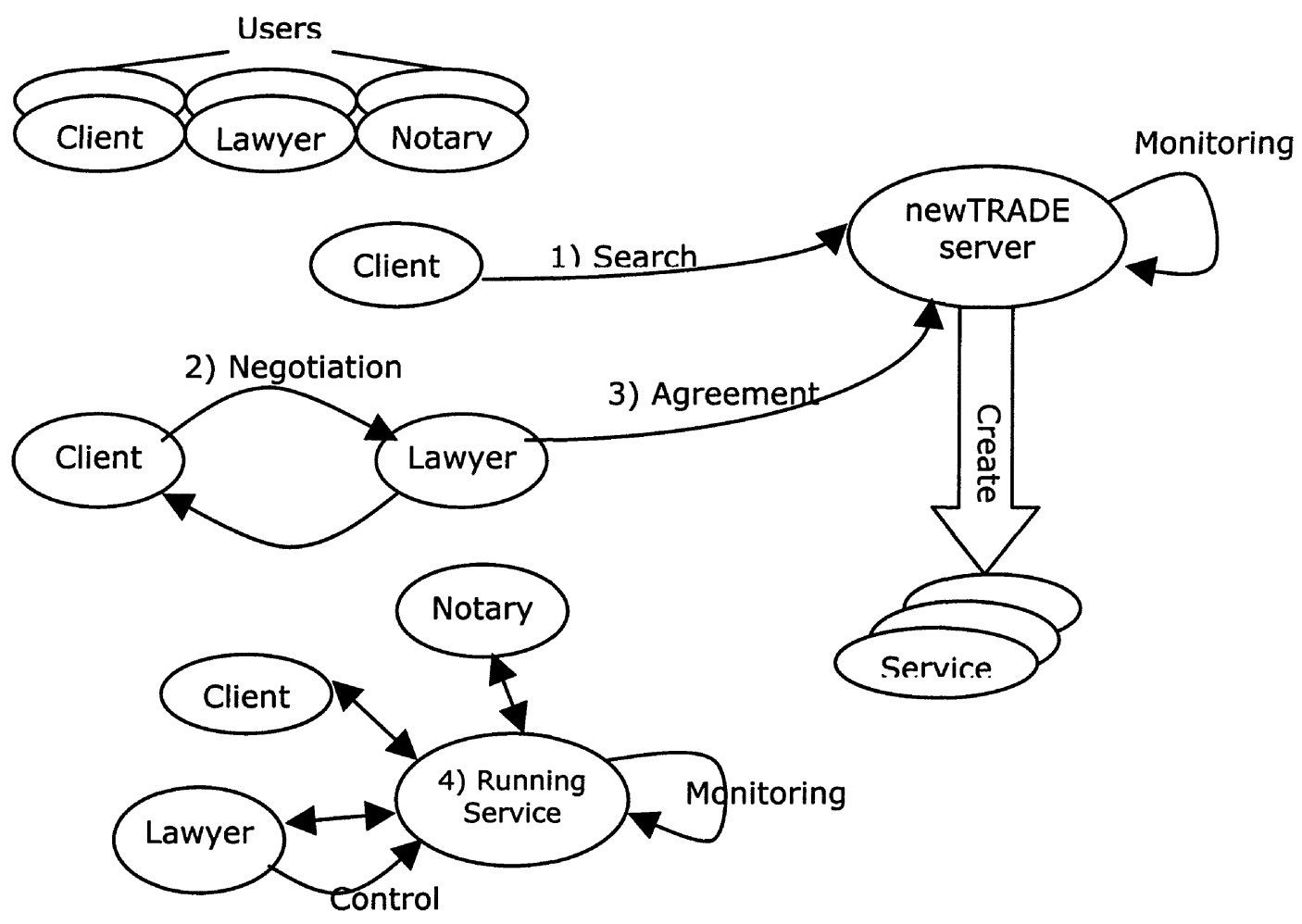

Figure 5. newTRADE functional model

To illustrate the operation of the TRADE system, we explain in 6.1 how an e-service is started.

\subsection{Interchange of information to start an e-service}

As an example of the use of our model, we are going to show the interchanges of information occurred in TRADE between a client and a professional (normally a lawyer) in order to start an e-service. This interchange is graphically shown in Figure 6, and the steps are specified next:

1. The client searches all the professionals accomplishing some criteria by calling to the server entity. The server entity calls the search operation from the metadata entity. The result is returned to the client.

2. The client selects one of the professionals returned by the server entity and sends him/her an explanation of his/her problem. This information is stored by the metadata entity and a result is returned. If the result is positive, the server entity sends a notification to the professional's notification entity.

3. The professional reads the notification and asks the server entity about the information sent by the client. 
4. The professional writes a response for the client (a positive response in this case). This response is stored in the metadata entity by the server entity and a notification is sent to the client's notification entity.

5. The client reads the notification and asks the server entity for the professional's response.

6. The client agrees with the response sent by the professional and accepts the e-service. The server entity stores the acceptance in the metadata entity and sends a notification to the professional's notification entity.

7. The professional reads the notification and starts the e-service. In order to start the e-service, the e-service information, the users and the documentation must be created. All this information is stored by the metadata entity. 


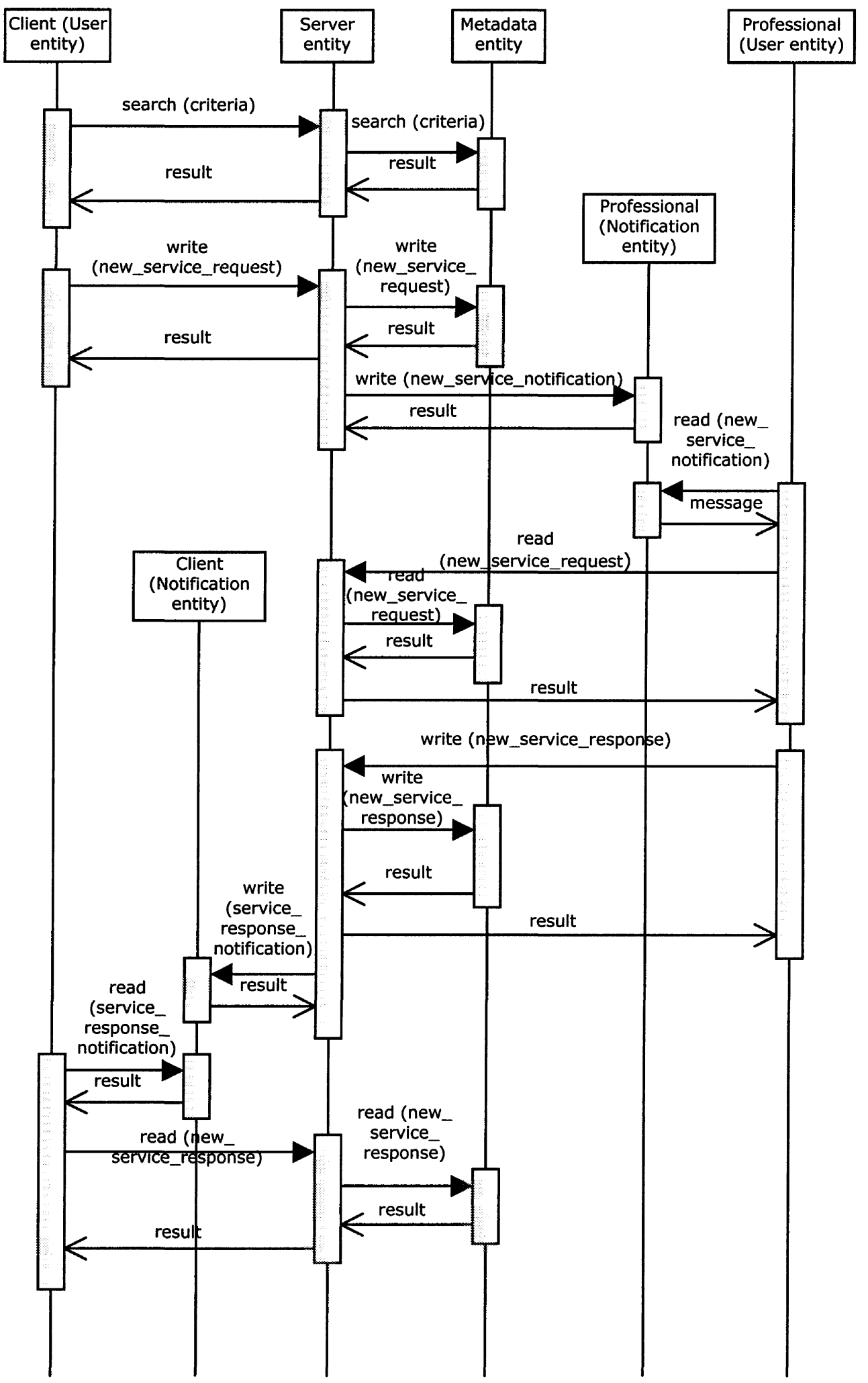


(Continuation of the diagram)

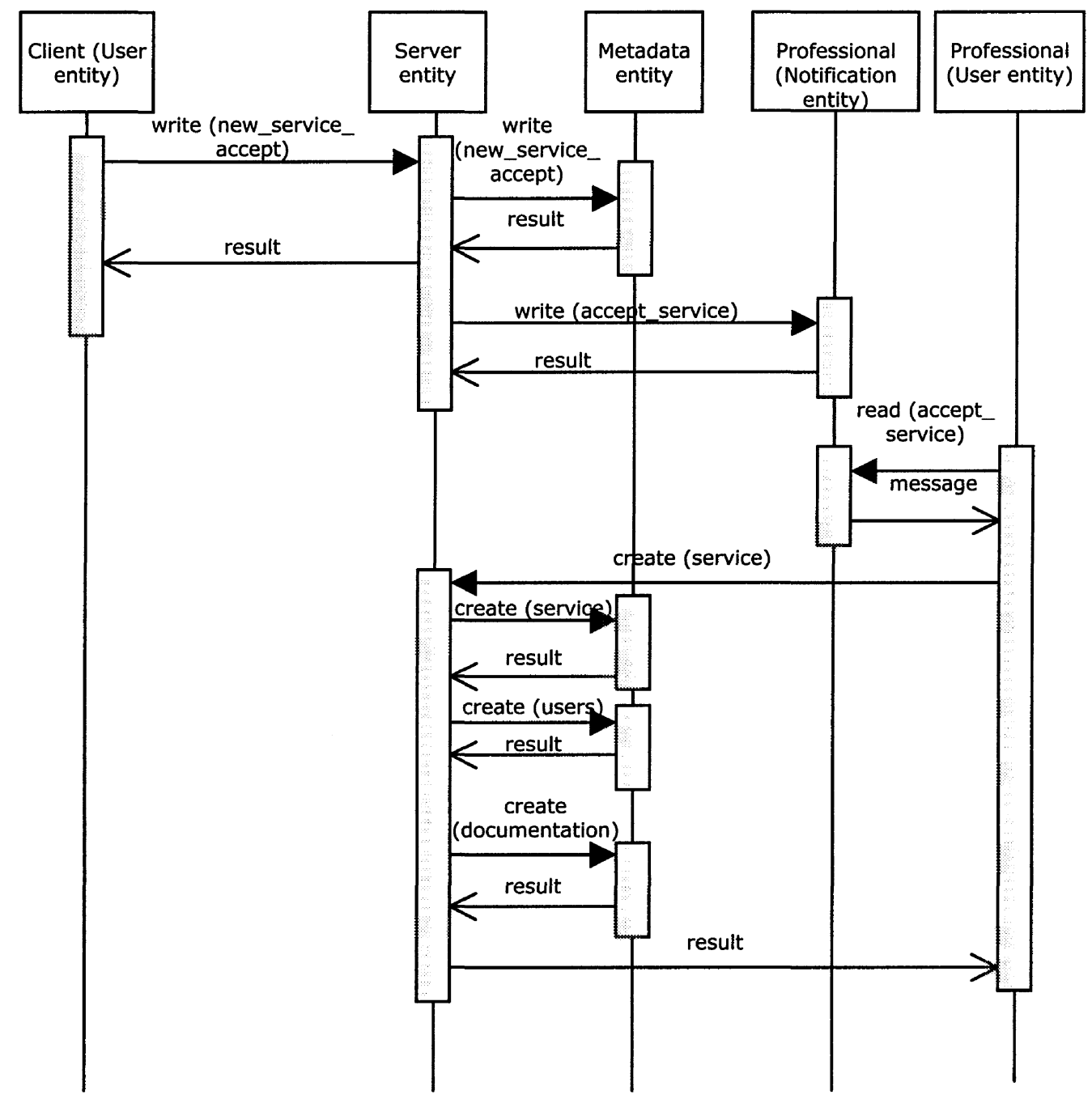

Figure 6. Interchange of information to start an e-service 


\section{CONCLUSIONS}

We have introduced electronic commerce of services (e-services) controlled by workflow. e-Services can be applied to any area inside e-commerce, e-government or e-business, and, in general, to any distributed system where several users must perform collaborative work interchanging information through open networks.

We have defined a formal way for expressing workflow information with the XML language, more precisely using DAML-S. Moreover, a method has been presented for the definition of workflow-based e-services. Inside this definition, we have shown which information is needed inside an e-service for its correct development. Related to this, a functional model has been presented, showing the entities that could be involved in an e-service.

Finally, we have presented an implemented system, the TRADE one, and new trends for the development of a new system using agent technologies.

\section{REFERENCES}

Gallego I., Delgado J. and Acebrón J.J. “Distributed models for brokerage on electronic commerce", International IFIP Working Conference Trends in Electronic Commerce (TREC'98), 3-5 June 98, Hamburg (Germany). Springer, ISBN 3-540-64564-0.

Schmid B. F. and Lindemman M. A., "Elements of a reference model for electronic markets", 31st Hawaiian International Conference on System Sciences (HICSS 1998), Jan. 1998, IEEE Press.

Workflow Management Coalition Web page, http://www.wfmc.org/.

W3C XML Web page, http://www.w3.org/XML/.

Hendler J. and McGuinness L. "Darpa Agent Markup Language”, IEEE Intelligent systems, 2001.

W3C RDF Web page, http://www.w3.org/RDF/.

DAML Services Coalition (Alphabetically, A. Ankolekar, M. Burstein, J. Hobbs, O. Lassila, D. Martin, S. McIlraith, S. Narayanan, M. Paolucci, T. Payne, K. Sycara and H. Zeng), "DAML-S: Semantic Markup for Web Services", Proceedings of the International Semantic Web Working Symposium (SWWS). July 30 - August 1, 2001, http://www.daml.org/services/SWWS.pdf.

ebXML Web page, http://www.ebxml.org/.

ITU-T Rec. T.192 COOPERATIVE DOCUMENT HANDLING: "Complex Services - Joint Synchronous Editing and Joint Document Presentation/Viewing", 1997.

Llorente S., Delgado J. and Polo J. "A methodology for the development of workflow based distributed systems", Proceedings of the IEEE International Conference in Telecommunications, ICT 2001 Bucharest (Romania), June 2001, ISBN 973-99995-1-4.

TRADE Web page, http://dmag.upf.es/flas_eng/peuropeos/trade.htm.

ACTS Web page, http://www.infowin.org/ACTS/.

Llorente S. and Delgado J. "Legal and administrative services through electronic commerce", $7^{\text {th }}$ International Conference on Intelligence in Services and Networks, IS\&N'2000 Athens (Greece), February 2000. Springer, ISBN 3-540-67152-8.

AREA2000 project (TIC2000-0317-P4-05), see DMAG Web page, http://dmag.upf.es/. 